\title{
Defining nutritional status of women in developing countries
}

\author{
Penelope Nestel and Shea Rutstein * \\ Demographic and Health Surveys, Macro International, Inc., 11785 Beltsville Drive, Calverton, MD 20705, USA
}

Submitted 10 July 2000: Accepted 20 July 2001

\begin{abstract}
Objective: To define a de facto reference body mass index (BMI) for women in developing countries and compare its performance with the Quetelet BMI.

Design: A logarithmic equation for elite wt/ht references was developed using the weight (wt) and height (ht) of 10524 non-pregnant elite mothers. Functional outcomes were compared using both BMIs.

Setting: Forty-six national surveys from 36 developing countries.

Subjects: Mothers 15-49 years old.

Results: The de facto reference standard deviation showed $2.2 \%$ of elite women were undernourished and 6.3\% overnourished; lower and upper limits for 'ideal' wt/ht were $73 \%$ and $137 \%$, respectively. Compared with the age-based and medium frame standards of the First and Second National Health and Nutrition Examination Surveys (NHANES I \& II), the de facto reference defined fewer women as undernourished (5.3\% vs. $10.5 \%$ and $14.4 \%$, respectively), but more as overnourished (20.4\% vs. $13.7 \%$ and $15.9 \%$, respectively). In the de facto reference, $\mathrm{BMI}=\mathrm{wt} / \mathrm{ht}^{1.6}$. Using the agebased and medium-frame-based Quetelet BMI (wt/ht ${ }^{2}$ ), 28.5\% and 31.7\% had a low and $13.0 \%$ and $14.7 \%$ a high BMI, respectively. For the de facto reference, $18.4 \%$ of the elite mothers had a low BMI and 19.3\% a high BMI. Applying the de facto reference to all women showed that the distribution of BMI was similar irrespective of the reference used. Functional outcomes were similar for both BMIs.

Conclusions: The NHANES I \& II growth curves define more women as overnourished than the de facto curve, but the opposite for defining the undernourished. Functional outcomes were similar for both BMIs, suggesting there is no great advantage to using a de facto BMI based on national-level data from these 46 national surveys.
\end{abstract}

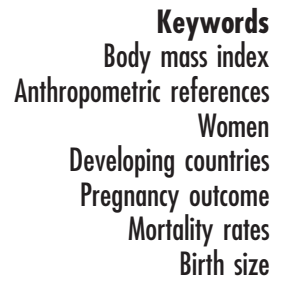

The Demographic and Health Survey Program (DHS) collects demographic and health data on women and their children. Maternal weight and height measurements are standard practice in the DHS, but problems have arisen in their use because no accepted international nutrition reference exists for adult women.

Site-specific studies have collected weight and height data on adult women in developing countries ${ }^{1-4}$. The purpose of these studies was to describe the population rather than produce a reference for assessing its nutritional status.

A number of reference data exist, including crosssectional representative data of 25-74-year-old noninstitutionalised US civilians in the First National Health and Nutrition Examination Survey (NHANES I, 19711974) and Second National Health and Nutrition Examination Survey (NHANES II, 1976-1980) ${ }^{5}$, the 1970-1972 Nutrition Canada National Survey ${ }^{6}$ and the 1980 United $^{5}$ Kingdom adult survey ${ }^{7}$. Frisancho ${ }^{5}$ gives the percentile distribution of weight-for-height by frame size for $25-54$ and 55-74 year olds, where frame size corresponds to
$<15$ th, 15th-85th and the 85th+ sex- and age-specific percentile of elbow breadth. Elbow breadth is relatively independent of adiposity and age ${ }^{8}$. The sex-specific Canadian reference data are available as percentile distributions of weight-for-height for five groups of 10-year age intervals covering 20-69 years. The United Kingdom reference data include tables of the percentage distribution of weight at each height for all ages and for the age groups 16-19, 20-29, 30-39, 40-49 and 50-64 years $^{8}$. The new Metropolitan Life Insurance height and weight tables are based on measurements of 25-59-yearold life insurance policyholders ${ }^{9}$. This reference is problematic for several reasons. (1) It is based on individuals who purchased life insurance from 25 companies in the USA and Canada. Policyholders were followed until the policy was cancelled, the individual died, or until the end of the study; thus, mortality rates varied with the follow-up period that was on average 6.6 years. (2) The weight and height tables do not refer to weights that minimise illness or incidence of disease. (3) Weight is related to an elbow-based definition of frame 
size - small, medium or large - that is assumed to represent $25 \%, 50 \%$ and $25 \%$ of the population, respectively. (4) The tables have no cut-off points for classification, either in terms of standard deviations - as with the NCHS/CDC/WHO standard for children ${ }^{10}-$ or in percentage of the median or percentiles. To our knowledge, none of the above reference data have been evaluated on a national population for developing countries.

Body mass indices (BMIs) have been developed using the ratio of weight to height. In the Quetelet index, a quadratic relationship between ideal weight (wt) and height (ht) - i.e. $\mathrm{BMI}=\mathrm{wt}(\mathrm{kg}) / \mathrm{ht}(\mathrm{m})^{2}-$ gives approximately the same value for short, medium and tall groups for the Fogarty standard ${ }^{11}$. Below $150 \mathrm{~cm}$ or $>190 \mathrm{~cm}$, however, BMI was strongly non-linear in its relationship with height ${ }^{12}$. The Fogarty standard, developed by the Metropolitan Life Insurance Company in the early 1940s, was based on mortality of US adults over 25 years old ${ }^{13,14}$. For 25-29 year olds, ideal weight corresponded to average weight. Because of the drawbacks in using the above references, standards and indices, we used the DHS maternal weight and height data to define a de facto reference for use in developing countries.

We also assess whether the BMI and de facto standard are associated with functional outcomes and compare their predictive performance.

\section{Methods}

The DHS are nationally representative surveys of women of reproductive age (15-49 years old). Weights and heights are collected for mothers with children $<5$ years old. Data are currently available for 46 surveys conducted between 1991 and 1998 in 36 countries. The surveys are implemented by national census and survey organisations with technical assistance from Macro International, Inc. Specially trained personnel, standardised prior to the implementation of fieldwork, take the anthropometric measurements. Continuous supervision of field operations is provided.

Mother's height is measured to the nearest $0.1 \mathrm{~cm}$ using a portable anthropometer made in the USA specifically for the DHS. Weight is measured to the nearest $0.1 \mathrm{~kg}$ using Seka battery-operated electronic scales. Mothers complete a questionnaire that includes social and economic characteristics of the household including her education, type of toilet, source of drinking water, type of floor material, ownership of a television, radio, refrigerator and electric cooker, availability of electricity, and type of transport owned, as well as basic demographic characteristics including her age, marital status, total number of times given birth and number of living children. Neonatal, infant and under-five mortality, birth weights, sizes at birth and pregnancy outcomes are also reported by each woman interviewed. Mortality data included in the analyses were restricted to the events that occurred in the preceding five years. No data were collected on maternal health conditions.

To compare the nutritional status of mothers with the NHANES I \& II reference data, an elite set of mothers was selected from all of the available mothers. In all countries except Bangladesh, Bolivia, the first Kenya survey, Malawi and Nepal, these mothers were defined as those who had attended at least secondary school, came from households that owned either a car or motorbike, and whose homes had both electricity and a fridge. In Bangladesh, Malawi and Nepal, data on whether households owned a fridge were not available. Similarly, in Bangladesh, Bolivia, the first Kenya survey and Nepal, data on whether households owned a motor vehicle were not available. For the above countries, owning a motor vehicle or having both electricity and a refrigerator were substituted by the availability of a flush toilet in the household.

Data were entered in computers using the Integrated Survey Systems Analysis software and analysed using SPSS $\mathrm{PC}+$ Version 10. Analysis of variance (ANOVA) was used to test whether the data came from normal populations with equal variances. 'Ideal' or predicted weight for a given height was determined from regression analyses after controlling for confounders.

\section{Results}

Height data are available for 11306 elite mothers and weight for 10573 non-pregnant elite mothers. Based on the distribution, and starting at $140 \mathrm{~cm}$, height was grouped into 14 categories in intervals of $2 \mathrm{~cm}$ except for both the first two and the last two categories, where intervals of $5 \mathrm{~cm}$ were used. Descriptive statistics for the weight of non-pregnant mothers were obtained for each height category. Within each height category, nonpregnant mothers whose weights were plus or minus four standard deviations ( $\pm 4 \mathrm{SD}$ ) above or below the median were excluded from the analysis because they were considered to be extreme and not representative of well-nourished women. Forty-six mothers were excluded because they fell outside the 4SD limits and another 11 mothers were excluded because they exceeded overall limits on weight $(<35 \mathrm{~kg}$ and $>130 \mathrm{~kg})$ and height $(<135 \mathrm{~cm}$ and $>180 \mathrm{~cm})$ as determined from scatter plots. After these exclusions, data from 10524 elite mothers were used to develop the de facto references.

Over $50 \%$ of the non-pregnant elite mothers came from seven country surveys: Uzbekistan (12.1\%), Kazakstan (10.6\%), 1996 Dominican Republic survey (9.3\%), Kyrgyz Republic (8.0\%), 1992/93 Egypt survey (7.7\%) and Nicaragua (6.5\%). Twenty-six countries each contributed less than 100 elite women, comprising $8.2 \%$ of the sample.

Among elite mothers, height was normally distributed: $158.0 \pm 6.3 \mathrm{~cm}($ mean $\pm \mathrm{SD})($ Table 1$)$. Compared with all 
Table 1 Descriptive statistics for height and weight of elite mothers by country

\begin{tabular}{|c|c|c|c|c|c|c|c|c|c|c|c|c|}
\hline \multirow[b]{2}{*}{ Country } & \multirow[b]{2}{*}{ Year } & \multirow[b]{2}{*}{$n$} & \multicolumn{5}{|c|}{ Height (cm) } & \multicolumn{5}{|c|}{ Weight (kg) } \\
\hline & & & Mean & SD & Median & Min & Max & Mean & SD & Median & Min & Max \\
\hline Bangladesh & 1996/97 & 235 & 152.4 & 5.9 & 152.3 & 139.5 & 180.0 & 51.3 & 10.1 & 49.6 & 35.2 & \\
\hline Benin & 1996 & 26 & 161.4 & 6.7 & 162.0 & 147.8 & 173.0 & 64.9 & 13.0 & 61.5 & 47.6 & 99 \\
\hline Bolivia & $1993 / 94$ & 178 & 154.3 & 5.8 & 154.1 & 136.6 & 177.0 & 56.8 & 8.9 & 55.7 & 43.1 & 93. \\
\hline Bolivia & 1998 & 435 & 154.9 & 5.9 & 154.6 & 142.2 & 175.1 & 60.6 & 10.3 & 59.1 & 38.2 & 105. \\
\hline Brazil & 1996 & 535 & 158.8 & 6.1 & 158.4 & 140.8 & 179.0 & 60.5 & 10.1 & 59.2 & 35.7 & 106. \\
\hline Burkina Faso & $1992 / 93$ & 88 & 163.9 & 5.6 & 163.8 & 150.0 & 178.0 & 67.8 & 13.8 & 65.6 & 44.5 & 105. \\
\hline Central African Republic & $1994 / 95$ & 19 & 160.2 & 7.0 & 160.2 & 150.0 & 179.1 & 58.6 & 13.7 & 54.7 & 44.0 & 93. \\
\hline Chad & $1996 / 97$ & 18 & 164.8 & 6.6 & 165.2 & 149.0 & 174.7 & 65.6 & 13.3 & 65.7 & 38.3 & 89 \\
\hline Colombia & 1995 & 324 & 156.4 & 5.6 & 156.2 & 140.3 & 173.1 & 60.2 & 10.0 & 59.6 & 40.7 & 104.9 \\
\hline Comoros & 1996 & 8 & 155.3 & 5.9 & 154.6 & 148.4 & 163.2 & 60.2 & 13.1 & 57.5 & 45.0 & 87.5 \\
\hline Cote d'Ivoire & 1994 & 43 & 160.8 & 6.0 & 159.9 & 149.5 & 178.0 & 62.4 & 11.1 & 62.9 & 43.9 & 87.8 \\
\hline Dominican Republic & 1991 & 205 & 157.7 & 5.6 & 157.5 & 143.6 & 173.9 & 60.0 & 10.8 & 58.4 & 38.7 & 100.0 \\
\hline Dominican Republic & 1996 & 975 & 157.7 & 6.0 & 157.4 & 139.1 & 179.9 & 60.5 & 11.9 & 58.6 & 35.7 & 111.4 \\
\hline Egypt & $1992 / 93$ & 778 & 158.9 & 5.6 & 159.0 & 139.0 & 179.2 & 72.6 & 12.8 & 71.2 & 38.0 & 120.8 \\
\hline Egypt & 1995/96 & 331 & 159.3 & 5.6 & 159.4 & 142.5 & 179.0 & 69.7 & 13.3 & 66.7 & 40.0 & 113.5 \\
\hline Ghana & 1993 & 21 & 160.3 & 5.5 & 159.1 & 150.4 & 170.6 & 70.4 & 12.1 & 71.0 & 49.3 & 90.2 \\
\hline Ghana & $1998 / 99$ & 11 & 160.9 & 5.5 & 159.4 & 154.5 & 175.1 & 76.3 & 13.2 & 76.2 & 54.7 & 99.9 \\
\hline Guatemala & 1995 & 182 & 154.4 & 5.7 & 154.1 & 140.5 & 170.0 & 61.4 & 10.9 & 60.3 & 36.6 & 98.5 \\
\hline Guatemala & $1998 / 99$ & 105 & 154.2 & 5.9 & 154.5 & 138.0 & 168.8 & 65.2 & 12.5 & 63.8 & 36.0 & 91.4 \\
\hline Haiti & 1994/95 & 35 & 159.9 & 4.9 & 159.9 & 150.0 & 170.5 & 62.2 & 12.2 & 59.1 & 43.7 & 86.9 \\
\hline Kazakstan & 1995 & 1110 & 159.6 & 5.8 & 159.6 & 142.2 & 179.4 & 63.7 & 14.0 & 60.8 & 38.0 & 128.2 \\
\hline Kenya & 1993 & 37 & 159.0 & 6.2 & 159.7 & 144.1 & 175.6 & 63.5 & 8.6 & 64.1 & 43.8 & 78.8 \\
\hline Kenya & 1998 & 32 & 160.4 & 5.6 & 160.3 & 151.5 & 173.4 & 61.0 & 10.9 & 59.5 & 45.7 & 93.6 \\
\hline Kyrgyz Republic & 1997 & 843 & 159.0 & 5.6 & 159.0 & 142.0 & 176.6 & 59.7 & 11.6 & 57.5 & 37.6 & 117.0 \\
\hline Madagascar & 1997 & 4 & 155.9 & 9.0 & 155.8 & 146.5 & 165.5 & 54.5 & 8.8 & 55.1 & 43.4 & 64.5 \\
\hline Malawi & 1992 & 17 & 160.9 & 5.2 & 160.0 & 153.5 & 169.5 & 67.3 & 13.5 & 66.7 & 41.7 & 95.3 \\
\hline Mali & $1995 / 96$ & 51 & 164.8 & 5.1 & 166.2 & 154.9 & 175.1 & 66.3 & 11.2 & 66.7 & 41.2 & 92.8 \\
\hline Morocco & 1992 & 136 & 159.4 & 5.1 & 159.1 & 147.1 & 173.0 & 64.9 & 11.9 & 62.3 & 42.4 & 94.0 \\
\hline Mozambique & 1997 & 21 & 158.5 & 6.2 & 158.3 & 147.7 & 171.0 & 62.1 & 10.1 & 64.1 & 43.8 & 75.5 \\
\hline Namibia & 1992 & 175 & 162.1 & 6.3 & 162.6 & 144.3 & 178.5 & 65.2 & 12.5 & 63.4 & 40.3 & 104.5 \\
\hline Nepal & 1996 & 36 & 152.2 & 4.7 & 153.6 & 136.3 & 160.1 & 49.2 & 7.0 & 49.1 & 36.1 & 64.0 \\
\hline Nicaragua & $1997 / 98$ & 684 & 156.6 & 5.6 & 156.4 & 138.7 & 173.6 & 60.5 & 11.3 & 59.0 & 36.2 & 99.2 \\
\hline Niger & 1992 & 44 & 163.9 & 6.1 & 163.7 & 152.3 & 179.5 & 71.7 & 11.9 & 73.1 & 43.2 & 94.6 \\
\hline Niger & 1998 & 43 & 161.5 & 4.7 & 160.7 & 149.4 & 171.5 & 66.7 & 13.1 & 66.3 & 44.8 & 104.1 \\
\hline Peru & 1991/92 & 365 & 154.2 & 6.2 & 154.3 & 140.6 & 179.2 & 58.9 & 9.2 & 58.5 & 38.7 & 88.3 \\
\hline Peru & 1996 & 600 & 153.9 & 5.7 & 153.7 & 139.7 & 171.6 & 61.1 & 10.1 & 60.6 & 35.2 & 110.1 \\
\hline Senegal & $1992 / 93$ & 39 & 164.9 & 5.2 & 165.4 & 153.3 & 174.8 & 70.1 & 12.1 & 67.2 & 45.4 & \\
\hline Tanzania & $1991 / 92$ & 11 & 161.4 & 5.6 & 162.4 & 150.8 & 170.0 & 71.5 & 12.9 & 70.5 & 53.4 & 93.6 \\
\hline Tanzania & 1996 & 24 & 159.3 & 6.0 & 159.4 & 146.0 & 169.5 & 66.5 & 10.0 & 66.7 & 45.3 & 86.0 \\
\hline Togo & 1998 & 36 & 162.7 & 4.9 & 162.9 & 150.0 & 172.0 & 64.2 & 11.1 & 63.2 & 47.8 & 93.0 \\
\hline Turkey & 1993 & 187 & 157.1 & 5.7 & 157.5 & 138.1 & 175.6 & 62.1 & 10.6 & 60.6 & 42.1 & 102.0 \\
\hline Uganda & 1995 & 12 & 159.9 & 8.1 & 162.6 & 145.9 & 171.8 & 67.0 & 12.3 & 67.4 & 46.8 & 90.6 \\
\hline Uzbekistan & 1996 & 1277 & 159.7 & 6.0 & 159.6 & 141.7 & 179.9 & 59.4 & 11.0 & 58.0 & 36.4 & 105.6 \\
\hline Zambia & 1992 & 53 & 159.4 & 6.1 & 159.0 & 147.5 & 173.1 & 62.5 & 12.8 & 63.2 & 41.1 & 96.2 \\
\hline Zambia & 1996 & 37 & 161.9 & 6.5 & 162.4 & 149.4 & 175.5 & 62.0 & 10.6 & 62.9 & 44.8 & 90.8 \\
\hline Zimbabwe & 1994 & 98 & 160.8 & 6.1 & 161.3 & 146.7 & 173.5 & 68.2 & 13.0 & 66.0 & 45.2 & 105.0 \\
\hline Total & & 10524 & 158.0 & 6.3 & 158.0 & 136.3 & 180.0 & 62.1 & 12.4 & 60.1 & 35.2 & 128.2 \\
\hline
\end{tabular}

mothers, elite mothers were $1.8 \mathrm{~cm}$ taller (Table 2). The Levene statistic, which tests for homogeneity of variance, showed that variances in height among the elite women were equal $(P=0.590)$. ANOVA showed that elite mother's height did not differ by age group based on 5-year intervals $(P=0.104)$.

Weight of elite mothers was also normally distributed: $62.1 \pm 12.4 \mathrm{~kg}$ (mean \pm SD) (Table 1). Overall, elite mothers were $5.8 \mathrm{~kg}$ heavier than all mothers (Table 2). Elite mothers put on weight with increasing age (Fig. 1); for any given height an older woman was more likely to be heavier than a younger woman.

The BMI for the median height and weight of the elite population was 24.1, which was slightly higher than the BMI for the median of the entire population at 22.4.

\section{Development of the de facto reference}

Median weights were calculated for each of the 14 elite women height categories. Regressing the median weights on the medians of the height categories using linear and quadratic functions gave $R^{2}$ values of 0.977 and 0.990, respectively. Both equations predicted similar weights for heights under $170 \mathrm{~cm}$, but beyond $170 \mathrm{~cm}$ the quadratic equation predicted lower weights than the linear equation. Figure 2 shows the age- and frame-based reference curves 
Table 2 Descriptive statistics for height and weight of all mothers by country

\begin{tabular}{|c|c|c|c|c|c|c|c|c|c|c|c|c|c|}
\hline \multirow[b]{2}{*}{ Country } & \multirow[b]{2}{*}{ Year } & \multicolumn{6}{|c|}{ Height (cm) } & \multicolumn{6}{|c|}{ Weight (kg) } \\
\hline & & $n$ & Mean & SD & Median & Min & Max & $n$ & Mean & SD & Median & Min & Max \\
\hline Bangladesh & $1996 / 97$ & 3694 & 150.8 & 5.3 & 150.6 & 135.0 & 180.0 & 3694 & 43.5 & 6.4 & 42.2 & 35.0 & 101. \\
\hline Benin & 1996 & 2263 & 158.4 & 6.1 & 158.3 & 138.3 & 178.3 & 2263 & 53.2 & 8.8 & 51.7 & 35.2 & 114. \\
\hline Bolivia & $1993 / 94$ & 2318 & 151.0 & 5.5 & 150.6 & 136.0 & 177.0 & 2362 & 55.3 & 9.3 & 53.5 & 35.0 & 121. \\
\hline Bolivia & 1998 & 4014 & 151.3 & 5.8 & 151.0 & 135.0 & 176.0 & 4014 & 58.1 & 9.9 & 56.6 & 37.0 & 129.0 \\
\hline Brazil & 1996 & 3059 & 156.3 & 6.4 & 156.0 & 135.7 & 179.0 & 3059 & 58.7 & 11.3 & 57.5 & 35.4 & 115.2 \\
\hline Burkina Faso & $1992 / 93$ & 3659 & 161.5 & 5.8 & 161.5 & 137.0 & 179.3 & 3660 & 54.8 & 8.2 & 53.8 & 35.0 & 124.4 \\
\hline Central African Republic & $1994 / 95$ & 2039 & 158.6 & 6.5 & 158.6 & 135.6 & 179.1 & 2039 & 52.9 & 8.0 & 51.9 & 35.2 & 98.0 \\
\hline Chad & $1996 / 97$ & 3736 & 162.5 & 6.2 & 162.4 & 136.0 & 180.0 & 3736 & 54.3 & 8.4 & 53.7 & 35.2 & 115.5 \\
\hline Colombia & 1995 & 3248 & 154.5 & 6.0 & 154.4 & 135.7 & 175.8 & 3248 & 58.5 & 10.2 & 57.3 & 35.7 & 111.3 \\
\hline Comoros & 1996 & 783 & 154.7 & 5.4 & 154.9 & 139.4 & 170 & 783 & 53.7 & 9.5 & 52.0 & 35.9 & 102.3 \\
\hline Cote d'Ivoire & 1994 & 3139 & 158.8 & 5.9 & 158.6 & 136.5 & 179.4 & 3138 & 55.8 & 9.3 & 54.3 & 36.2 & 112.3 \\
\hline Dominican Republic & 1991 & 2073 & 156.4 & 5.8 & 156.3 & 135.4 & 175 & 2080 & 56.6 & 11.0 & 55.1 & 35.3 & 115. \\
\hline Dominican Republic & 1996 & 7422 & 156.8 & 6.1 & 156.7 & 135.8 & 17 & 7422 & 59.8 & 12.4 & 57.8 & 35.0 & 125. \\
\hline Egypt & $1992 / 93$ & 4787 & 156.9 & 5.5 & 157.1 & 139.0 & $17 \mathrm{~s}$ & 4785 & 66 & 13.8 & 64.2 & 35.4 & 129. \\
\hline Egypt & $1995 / 96$ & 6590 & 157.5 & 5.9 & 157.5 & 135.3 & 179 & 6595 & 65.3 & 13.2 & 63.0 & 35.9 & 129.5 \\
\hline Ghana & 1993 & 1764 & 158.5 & 5.7 & 158.4 & 139.3 & 179.4 & 1765 & 54.7 & 9.4 & 53.2 & 35.8 & 104.5 \\
\hline Ghana & $1998 / 99$ & 2007 & 158.5 & 6.0 & 158.4 & 136.3 & 177.0 & 2007 & 55.5 & 10.4 & 53.3 & 35.7 & 114.6 \\
\hline Guate & 1995 & 4663 & 148.3 & 6.1 & 147 & 135 & & 4663 & 53.4 & 10.3 & 51.1 & 35.0 & 116.0 \\
\hline Guatemala & 1998/99 & 2268 & 148.5 & 6.1 & 148.2 & 135.0 & $16 \mathrm{~s}$ & 2268 & 55.3 & 11.2 & 52.9 & 35.0 & 106.0 \\
\hline Haiti & $1994 / 95$ & 1897 & 158.5 & 6.3 & 158.5 & 136.3 & 177.1 & 1896 & 53.3 & 9.2 & 52.0 & 35.1 & 107.8 \\
\hline Kazakstan & 1995 & 3546 & 159.0 & 5.9 & 159.0 & 138.4 & 179 & 3546 & 62.6 & 14.4 & 59.5 & 35.4 & 128.5 \\
\hline Kenya & 1993 & 3368 & 159.2 & 6.1 & 159.0 & 138.5 & 180 & 3366 & 55.7 & & 54.5 & 35.3 & 109.5 \\
\hline Kenya & 1998 & 3243 & 160.0 & 6.1 & 159.7 & 136.0 & & 3243 & 56.1 & & 55.0 & 35.2 & 103.5 \\
\hline Kyrgyz Republic & 1997 & 3566 & 157.9 & 5.7 & 158.0 & 137.0 & 178.0 & 3566 & 58.4 & 11.3 & 56.0 & 36.0 & 123.0 \\
\hline Madagascar & 1997 & 2747 & 152.9 & 5.7 & 152.8 & 136.9 & 172.2 & 2747 & 47.8 & 6.6 & 47.0 & 35.0 & 95.3 \\
\hline Malawi & 1992 & 2358 & 156.0 & 5.6 & 156.0 & & & 2358 & 52 & & 51 & 35.2 & 129.3 \\
\hline Mali & $1995 / 96$ & 4308 & 161.3 & 6.1 & 161.3 & 136 & & 4308 & 55 & 8. & 53 & 35.3 & 112.0 \\
\hline Morocco & 1992 & 2881 & 157.0 & 5.5 & 157.0 & 135.6 & 179.0 & 2881 & 59.3 & 11.4 & 57.2 & 36.5 & 114.4 \\
\hline Mozambique & 1997 & 3262 & 155.5 & 6.2 & 155.4 & 136.0 & 178.1 & 3262 & 52.1 & 8.3 & 51.2 & 35.2 & 112.8 \\
\hline Namibia & 1992 & 2273 & 160.5 & 6.3 & 160.5 & 135.3 & 17 & 2228 & 58.2 & 12.0 & 56.0 & 35.6 & 122.4 \\
\hline Nepal & 1996 & 3287 & 150.6 & 5.2 & 150.5 & 135.5 & 175 & 3287 & 45.2 & 5. & 44 & 35.0 & 87.1 \\
\hline Nicaragua & $1997 / 98$ & 12273 & 154.1 & 5.8 & 154.0 & 135.0 & 179.4 & 12273 & 59.2 & 12.0 & 57.2 & 35.0 & 128.0 \\
\hline Niger & 1992 & 3435 & 160.2 & 6.0 & 160.1 & 135.9 & 180.0 & 3435 & 53.4 & 8.8 & 52.1 & 35.3 & 118.2 \\
\hline Niger & 1998 & 3566 & 160.2 & 5.9 & 160.0 & 141.7 & 178.9 & 3566 & 53.2 & 8.8 & 51.7 & 35.4 & 115.5 \\
\hline Peru & 1991/92 & 4811 & 150.3 & 5.6 & 150.1 & 135.0 & & 4808 & 56.0 & 9.1 & 54.5 & 35.8 & 111.5 \\
\hline Per & 1996 & 9892 & 150.5 & 5.6 & 150.2 & 135.0 & 179.3 & 9892 & 56.8 & 9.2 & 55.4 & 35.0 & 112.3 \\
\hline Senegal & $1992 / 93$ & 2941 & 162.3 & 5.8 & 162.1 & 142.3 & 179.5 & 2936 & 57.6 & 10.4 & 55.8 & 36.2 & 122.2 \\
\hline Tanzania & 1991/92 & 4499 & 155.9 & 6.2 & 155.6 & 136.5 & 179.7 & 4492 & 52.8 & 8.2 & 51.7 & 35.0 & 101.0 \\
\hline Tanzania & 1996 & 3808 & 156.3 & 6.1 & 156.0 & 135.3 & 178.0 & 3808 & 53.7 & 8.9 & 52.4 & 35.3 & 110.7 \\
\hline Togo & 1998 & 3186 & 158.6 & 5.9 & 158.4 & 138.0 & 179.9 & 3186 & 54.4 & 9.1 & 52.9 & 35.7 & 119.4 \\
\hline Turkey & 1993 & 2395 & 155.3 & 5.5 & 155.2 & 135.4 & 180.0 & 2395 & 62.2 & 12.1 & 60.5 & 36.4 & 121.0 \\
\hline Uganda & 1995 & 3381 & 158.2 & 6.3 & 158.2 & 135.5 & 180.0 & 3380 & 53.8 & 7.5 & 53.0 & 35.7 & 104.8 \\
\hline Uzbekistan & 1996 & 4069 & 159.3 & 6.2 & 159.0 & 138.0 & 180.0 & 4071 & 57.6 & 10.4 & 55.8 & 35.2 & 125.3 \\
\hline Zambia & 1992 & 3282 & 158.1 & 5.9 & 158.1 & 138.4 & 179.2 & 3274 & 54.6 & 9.1 & 53.2 & 35.2 & 106.2 \\
\hline Zambia & 1996 & 3849 & 158.1 & 6.0 & 158.0 & 137.5 & 179.5 & 3849 & 54.9 & 8.9 & 53.5 & 35.0 & 124.4 \\
\hline Zimbabwe & 1994 & 1908 & 159.3 & 5.9 & 159.2 & 139.9 & 178.2 & 1912 & 58.7 & 10.3 & 57.0 & 35.0 & 126.5 \\
\hline Total & & 167557 & 156.2 & 7.0 & 156.2 & 135.0 & 180.0 & 167544 & 56.3 & 11.0 & 54.4 & 35.0 & 130.0 \\
\hline
\end{tabular}

from NHANES I \& II plotted alongside the elite quadratic growth curve.

To establish the predictability of a de facto reference and to provide information on SDs, weight was regressed on height using the pooled individual data rather than summarised data. An ANOVA for height by country was carried out to determine whether genetic and socioeconomic variations resulted in differences in stature that could affect the analysis of weight-for-height. This analysis showed that height differed by country $(F=53.09$, $P=0.000$ ). Elite mothers in Senegal, Mali, Chad, Niger, Burkina Faso and Togo were taller than mothers in the other countries while those in Nepal, Bangladesh, Peru,
Guatemala and Bolivia were shorter than elsewhere (Table 1). Thus, nationality was included in the regression to predict weight. The Dominican Republic was taken as the reference category because mean height of the elite mothers in that country was closest to the overall mean for all elite mothers.

To control for the effect of age on weight, mother's age group was included in the individual regression equations. Mother's age was grouped into 5-year intervals except for age 40-49 years, which was taken as one group due to smaller numbers. Age grouping rather than a single continuous variable was used so that a simple tabular adjustment for age could be applied when using the de 


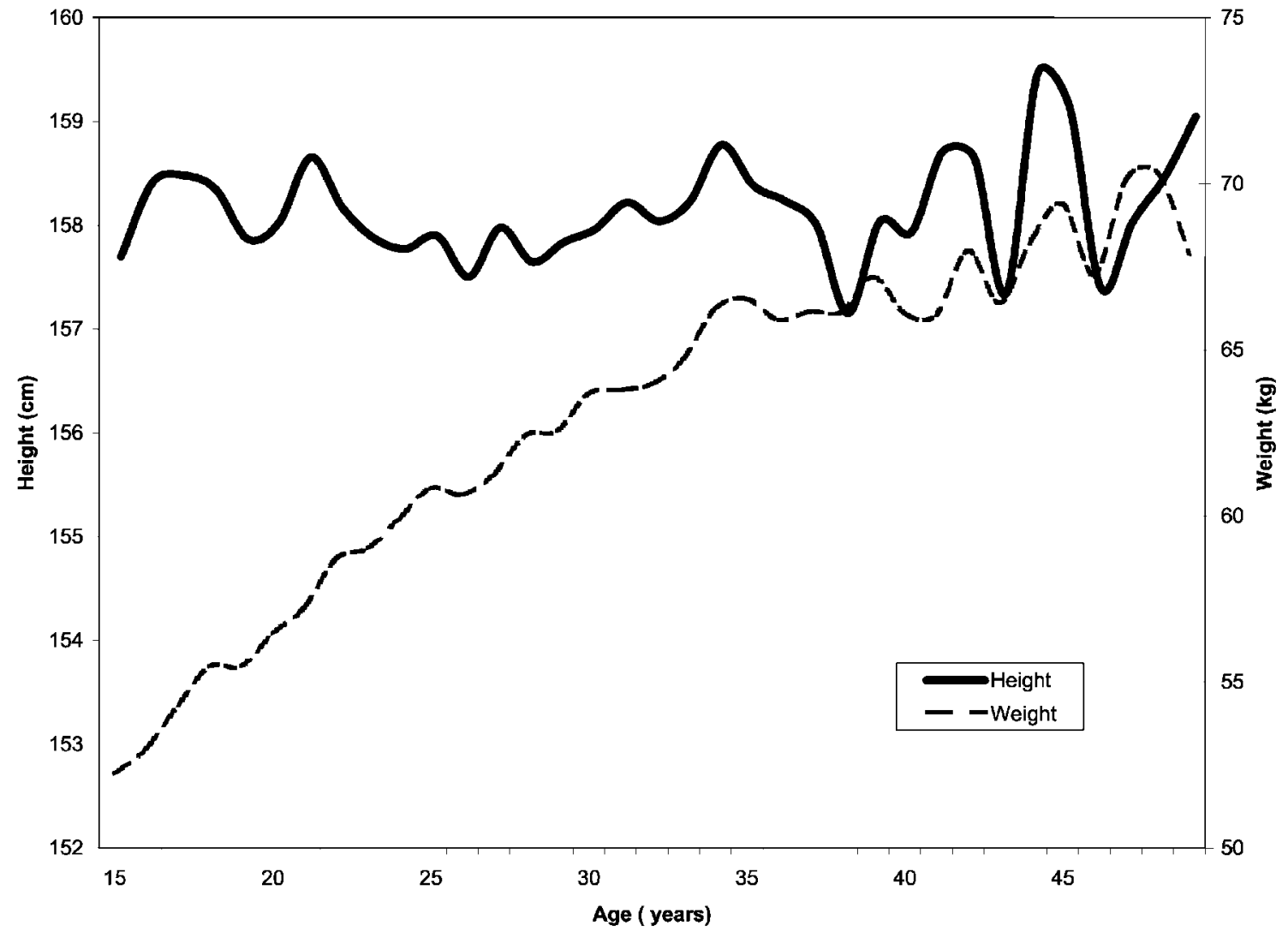

Fig. 1 Mean height and weight of elite mothers by age

facto reference. Also, using dummy variables for age groups allows greater flexibility than using a single function on age. Mothers of age 25-29 years were used as the control group. Because equation intercept is sensitive to the mix of countries and country sample size, country dummy variables were included to control this variation, with the Dominican Republic used as the reference group.

Controlling for both nationality and age group, a linear equation was estimated to develop the elite wt/ht reference. The residuals from the linear equation showed
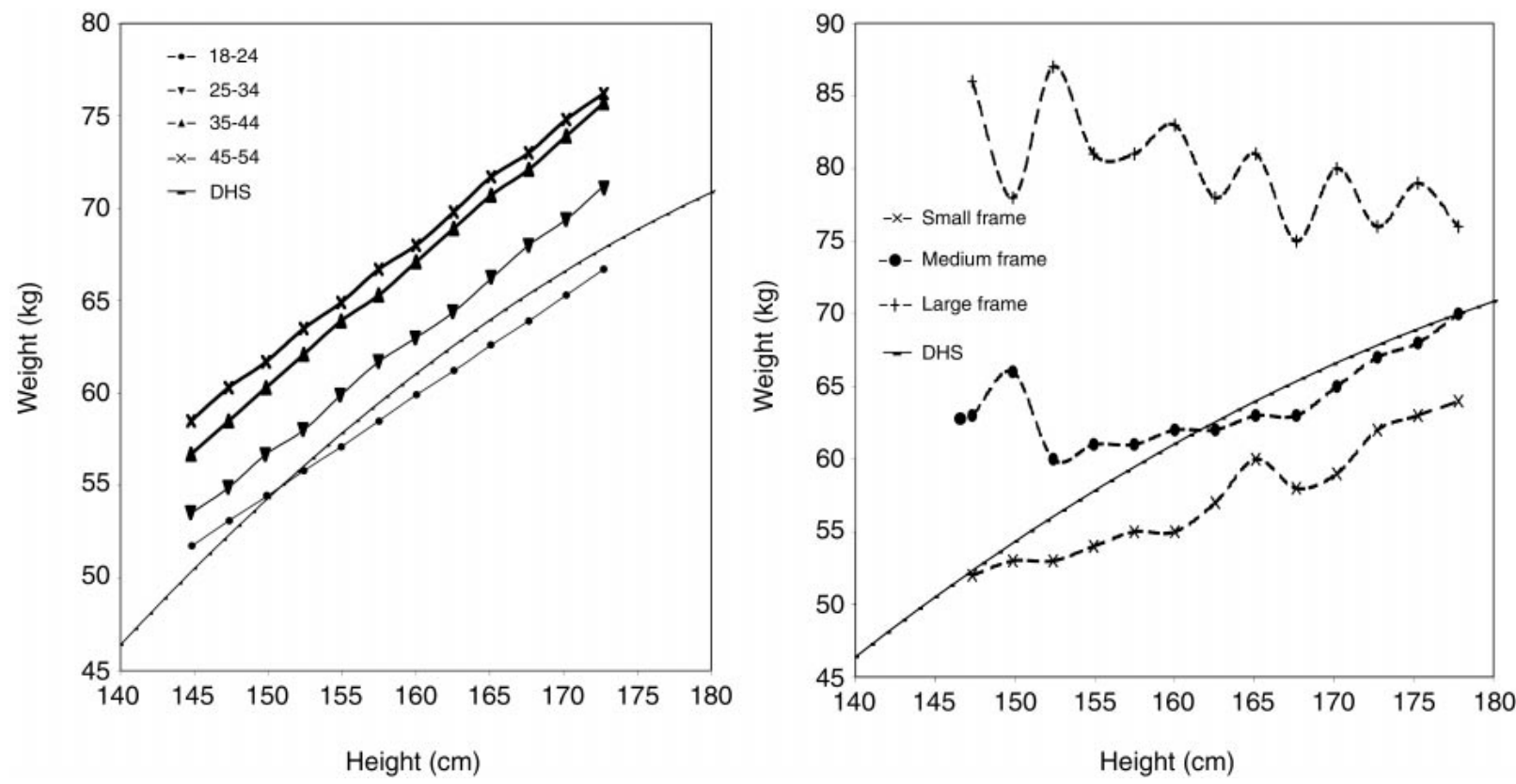

Fig. 2 Age-based and frame-based weight-for-height NHANES references for women compared with the de facto standard regression 
substantial heteroscedasticity, resulting in small $t$-values. To control for this, a multiplicative model - i.e. $\mathrm{wt}=a \times \mathrm{ht}^{b}-$ was used. The logarithmic form of this equation was estimated with the following results:

$$
\begin{aligned}
& \log _{10}(\mathrm{wt})=1.45+1.63 \log _{10}(\mathrm{ht})+A+C, \quad R^{2}=0.316 \\
& t \text {-value } \quad(166.21) \quad(37.97)
\end{aligned}
$$

where $\log _{10}(\mathrm{wt})$ and $\log _{10}(\mathrm{ht})$ are the logarithms of weight and height, respectively; $A=-0.041 \quad(t=-16.15)$, $-0.009(t=-8.21), \quad 0.0,0.004 \quad(t=8.04), 0.007 \quad(t=$ $14.58)$ and $0.008(t=19.89)$ for mothers' ages $15-19$, $20-24,25-29,30-34,35-39$ and 40-49 years, respectively; and $C=$ country (see Appendix). The residuals from this equation were examined by regressing them on the square of the $\log _{10}(\mathrm{ht})$. The resulting equation was not significant $(P=0.841)$. An additional examination of the interaction between country and $\log _{10}($ ht $)$ was made and, except for Namibia $(P=0.049)$, none were significant.

To establish $Z$-scores for the de facto equation, SDs were calculated for the residuals from the logarithmic equation and regressed across the 14 height groups. As expected, the association with height was not significant. Rather than use the SD of the residuals taken directly from the regression results (0.06923), the mean for the SDs for the height groups was used (0.06830). The mean was chosen to give equal weight to each of the height groups, rather than a weighting determined by the number of women in the sample in each of the height groups. \pm 2 SD were taken as the cut-off points for under- and overnutrition and are equal to a lower limit of $73 \%$ and an upper limit of $137 \%$ of the 'ideal' weight, respectively.

\section{Nutrition status}

Women $<145 \mathrm{~cm}$ or $<45 \mathrm{~kg}$ are classified as being at

Table 3 Distribution of NHANES I \& II and DHS de facto wt/ht reference standards of elite mothers $(n=10524)$

\begin{tabular}{lccc}
\hline & $\begin{array}{c}\text { NHANES } \\
\text { NHANES } \\
\text { I \& II } \\
\text { of median }\end{array}$ & $\begin{array}{c}\text { I \& II } \\
\text { (medium }\end{array}$ & \\
weight-for-height & $\begin{array}{c}\text { (age-based) } \\
\text { (\%) }\end{array}$ & $\begin{array}{c}\text { (\%) }) \\
(\%)\end{array}$ & $\begin{array}{c}\text { DHS de facto } \\
(\%)\end{array}$ \\
\hline $50-59$ & 0.1 & 0.3 & 0.0 \\
$60-69$ & 1.6 & 3.0 & 0.5 \\
$70-79$ & 8.8 & 11.1 & 4.8 \\
$80-89$ & 20.1 & 19.4 & 15.3 \\
$90-99$ & 24.9 & 22.0 & 22.8 \\
$100-109$ & 19.1 & 17.2 & 21.9 \\
$110-119$ & 11.7 & 11.3 & 14.3 \\
$120-129$ & 6.7 & 7.4 & 9.4 \\
$130-139$ & 3.8 & 3.9 & 5.1 \\
$140-149$ & 1.9 & 2.5 & 3.2 \\
$150-159$ & 0.9 & 1.2 & 1.4 \\
$160-169$ & 0.3 & 0.5 & 0.8 \\
$170-179$ & 0.1 & 0.3 & 0.4 \\
$180-189$ & 0.0 & 0.1 & 0.1 \\
& 100.0 & 100.0 & 100.0 \\
Total & & & \\
\hline
\end{tabular}

high risk for an adverse pregnancy outcome ${ }^{15}$. According to these criteria, among the 10524 DHS elite nonpregnant mothers, $0.5 \%$ were both short and thin, $1.9 \%$ were short only, $4.6 \%$ were thin only $(<45 \mathrm{~kg})$, and $94.0 \%$ were neither short nor thin. Table 3 shows the distributions of nutritional status using the different wt/ht indices.

The logarithmic regression between predicted weight and height for the de facto reference gave a de facto BMI for height using the power of 1.63, i.e. de facto $\mathrm{BMI}=\mathrm{wt} / \mathrm{ht}^{1.6}$.

James et al. ${ }^{16}$ classify undernutrition using the Quetelet BMI using three cut-off points, namely 16.0, 17.0 and 18.5. The World Health Organization ${ }^{10}$ classifies overnutrition using the cut-off points 25.0, 30.0 and 40.0. We adjusted these cut-off points for the average $\mathrm{wt} / \mathrm{ht}$ ratio and applied them to the median wt/ht of the NHANES I \& II age-based and medium frame references and to the median wt/ht for the de facto BMI (Table 4). Among elite mothers, 28.5\% and $13.0 \%$ were classified as having a low and high BMI, respectively, using the Quetelet BMI for the NHANES I \& II age-based reference; $31.7 \%$ and $14.7 \%$ were classified as having a low and high BMI, respectively, using the Quetelet BMI for the NHANES I \& II medium frame reference; and $18.4 \%$ of the elite mothers were classified as being low in wt/ht and $19.3 \%$ as being high for the de facto BMI.

Natural cut-off points can be derived from the distribution of the elite mothers by using $\pm 2 \mathrm{SD}$ of $\log _{10}$ (wt). Using these cut-offs, $2.2 \%$ of the elite mothers were defined as undernourished and 6.3\% as overnourished.

The distributions of BMI using both indices for all mothers in the 46 national surveys are shown in Table 5. According to the averages of Quetelet and de facto BMIs, 9-10\%, 64-65\% and 25-26\% of mothers were classified as being undernourished, normal and overnourished using each index, respectively. With the exception of Bangladesh and Nepal, where more women were classified as undernourished using the de facto BMI, the distribution of nutritional status was similar for the de facto and the Quetelet BMI.

Table 4 Undernutrition of elite mothers using NHANES I \& II Quetelet and DHS de facto BMI $(n=10524)$

\begin{tabular}{lccc}
\hline & $\begin{array}{c}\text { NHANES } \\
\text { I \& II } \\
\text { (age-based) } \\
(\%)\end{array}$ & $\begin{array}{c}\text { NHANES } \\
\text { I \& II } \\
\text { (medium } \\
\text { frame) } \\
(\%)\end{array}$ & $\begin{array}{c}\text { DHS de facto } \\
(\%)\end{array}$ \\
BMI & 6.7 & 10.2 & 3.1 \\
Very low (<16) & 6.8 & 8.2 & 4.2 \\
Moderately low (16-16.9) & 15.0 & 13.3 & 11.1 \\
Slightly low (17-18.4) & 58.6 & 53.6 & 62.4 \\
Normal (18.5-24.9) & 10.8 & 11.6 & 15.2 \\
Slightly high (25-29.9) & 2.2 & 3.1 & 4.1 \\
Moderately high (30-39.9) & 0.0 & 0.0 & 0.0 \\
Very high (40+) & 100.0 & 100.0 & 100.0 \\
Total & & & \\
\hline
\end{tabular}


Table 5 Undernutrition of mothers by country using Quetelet and DHS de facto BMI

Quetelet BMI

De facto BMI

Country Year $n \quad$ Very low Mod low Low Normal High Mod high Very high Total Very low Mod low Low Normal High Mod high Very high Total

\begin{tabular}{|c|c|c|c|c|c|c|c|c|c|c|c|c|c|c|c|c|c|c|}
\hline Bangladesh & 1996/97 & 3695 & 4.4 & 12.9 & 29.3 & 50.4 & 2.4 & 0.5 & 0.1 & 100.0 & 6.9 & 13.2 & 36.0 & 41.2 & 2.2 & 0.4 & 0.0 & 100.0 \\
\hline Benin & 1996 & 2262 & 0.9 & 2.2 & 11.3 & 76.5 & 7.0 & 1.9 & 0.1 & 100.0 & 0.8 & 1.5 & 12.7 & 75.6 & 7.5 & 1.8 & 0.1 & 100.0 \\
\hline Bolivia & $1993 / 94$ & 2313 & 0.0 & 0.3 & 1.8 & 64.3 & 26.1 & 7.1 & 0.5 & 100.0 & 0.0 & 0.3 & 2.1 & 67.7 & 23.5 & 6.0 & 0.3 & 100.0 \\
\hline Bolivia & 1998 & 4014 & 0.0 & 0.2 & 0.6 & 52.5 & 35.5 & 10.8 & 0.4 & 100.0 & 0.1 & 0.1 & 1.1 & 55.7 & 33.1 & 9.5 & 0.4 & 100.0 \\
\hline Brazil & 1996 & 3058 & 0.3 & 1.1 & 4.8 & 59.1 & 25.0 & 9.3 & 0.4 & 100.0 & 0.3 & 0.9 & 5.6 & 58.9 & 24.9 & 9.2 & 0.3 & 100.0 \\
\hline Burkina Faso & $1992 / 93$ & 3660 & 1.0 & 2.3 & 11.7 & 78.3 & 5.9 & 0.8 & 0.1 & 100.0 & 0.8 & 1.5 & 11.8 & 78.2 & 6.8 & 0.8 & 0.1 & 100.0 \\
\hline Central African Republic & $1994 / 95$ & 2039 & 0.7 & 2.0 & 12.1 & 78.7 & 5.5 & 1.0 & 0.0 & 100.0 & 0.6 & 1.8 & 13.3 & 77.3 & 5.6 & 1.3 & 0.0 & 100.0 \\
\hline Chad & $1996 / 97$ & 3736 & 2.1 & 4.4 & 14.3 & 74.0 & 4.4 & 0.8 & 0.0 & 100.0 & 1.9 & 3.1 & 15.0 & 73.5 & 5.6 & 0.9 & 0.0 & 100.0 \\
\hline Colombia & 1995 & 3248 & 0.1 & 0.5 & 3.1 & 55.8 & 31.4 & 8.9 & 0.3 & 100.0 & 0.1 & 0.4 & 3.8 & 56.3 & 31.0 & 8.2 & 0.3 & 100.0 \\
\hline Comoros & 1996 & 783 & 0.5 & 1.4 & 7.9 & 70.1 & 16.0 & 4.0 & 0.1 & 100.0 & 0.6 & 1.3 & 9.5 & 69.5 & 15.3 & 3.7 & 0.1 & 100.0 \\
\hline Cote d'Ivoire & 1994 & 3137 & 0.3 & 1.4 & 6.3 & 77.9 & 11.1 & 2.8 & 0.1 & 100.0 & 0.3 & 1.1 & 7.0 & 76.9 & 11.7 & 3.0 & 0.1 & 100.0 \\
\hline Dominican Republic & 1991 & 2069 & 0.5 & 1.8 & 6.3 & 65.7 & 18.7 & 6.4 & 0.4 & 100.0 & 0.7 & 1.4 & 8.0 & 64.1 & 19.3 & 6.1 & 0.3 & 100.0 \\
\hline Dominican Republic & 1996 & 7422 & 0.5 & 1.1 & 5.8 & 54.4 & 26.1 & 11.2 & 0.8 & 100.0 & 0.4 & 1.1 & 6.8 & 53.1 & 26.8 & 11.0 & 0.7 & 100.0 \\
\hline Egypt & $1992 / 93$ & 4782 & 0.0 & 0.1 & 1.2 & 41.3 & 34.0 & 21.3 & 2.2 & 100.0 & 0.1 & 0.1 & 1.5 & 40.5 & 34.3 & 21.4 & 2.0 & 100.0 \\
\hline Egypt & $1995 / 96$ & 6588 & 0.1 & 0.2 & 1.1 & 46.7 & 31.7 & 18.2 & 1.9 & 100.0 & 0.0 & 0.2 & 1.4 & 45.3 & 33.3 & 18.0 & 1.8 & 100.0 \\
\hline Ghana & 1993 & 1764 & 0.5 & 1.8 & 9.0 & 76.2 & 9.2 & 3.2 & 0.1 & 100.0 & 0.5 & 1.2 & 10.1 & 74.8 & 10.1 & 3.2 & 0.1 & 100.0 \\
\hline Ghana & $1998 / 99$ & 2006 & 0.5 & 1.3 & 9.2 & 73.1 & 11.1 & 4.6 & 0.1 & 100.0 & 0.5 & 0.9 & 10.5 & 71.9 & 11.3 & 4.7 & 0.1 & 100.0 \\
\hline Guatemala & 1995 & 4662 & 0.2 & 0.4 & 2.7 & 62.4 & 26.4 & 7.6 & 0.4 & 100.0 & 0.2 & 0.6 & 4.0 & 65.2 & 23.1 & 6.5 & 0.4 & 100.0 \\
\hline Guatemala & $1998 / 99$ & 2268 & 0.2 & 0.1 & 1.3 & 54.5 & 31.7 & 11.6 & 0.6 & 100.0 & 0.2 & 0.2 & 3.3 & 57.2 & 28.5 & 10.1 & 0.4 & 100.0 \\
\hline Haiti & $1994 / 95$ & 1896 & 1.5 & 3.6 & 13.2 & 70.5 & 8.9 & 2.4 & 0.0 & 100.0 & 1.4 & 2.8 & 14.7 & 69.2 & 9.4 & 2.4 & 0.0 & 100.0 \\
\hline Kazakstan & 1995 & 3546 & 0.5 & 1.2 & 6.0 & 53.8 & 21.9 & 14.7 & 1.9 & 100.0 & 0.6 & 1.0 & 6.4 & 52.4 & 22.8 & 15.1 & 1.8 & 100.0 \\
\hline Kenya & 1993 & 3363 & 0.6 & 1.3 & 8.1 & 76.2 & 11.4 & 2.2 & 0.1 & 100.0 & 0.7 & 1.0 & 8.9 & 74.1 & 12.8 & 2.4 & 0.1 & 100.0 \\
\hline Kenya & 1998 & 3244 & 0.6 & 1.9 & 9.2 & 73.5 & 12.2 & 2.5 & 0.1 & 100.0 & 0.6 & 1.4 & 9.8 & 72.5 & 12.8 & 2.7 & 0.1 & 100.0 \\
\hline Kyrgyz Republic & 1997 & 3566 & 0.3 & 1.3 & 5.2 & 65.6 & 19.1 & 8.0 & 0.4 & 100.0 & 0.3 & 1.1 & 5.7 & 65.1 & 19.5 & 7.9 & 0.5 & 100.0 \\
\hline Madagascar & 1997 & 2748 & 0.9 & 3.1 & 15.6 & 76.7 & 3.3 & 0.4 & 0.0 & 100.0 & 1.3 & 3.2 & 20.3 & 71.7 & 3.1 & 0.4 & 0.0 & 100.0 \\
\hline Malawi & 1992 & 2358 & 0.3 & 1.4 & 7.5 & 81.8 & 8.0 & 0.9 & 0.1 & 100.0 & 0.6 & 1.1 & 9.4 & 79.7 & 8.4 & 0.8 & 0.1 & 100.0 \\
\hline Mali & $1995 / 96$ & 4308 & 1.2 & 3.0 & 11.7 & 75.7 & 7.2 & 1.2 & 0.0 & 100.0 & 1.0 & 2.3 & 11.9 & 75.3 & 8.1 & 1.4 & 0.0 & 100.0 \\
\hline Morocco & 1992 & 2881 & 0.1 & 0.5 & 3.1 & 63.7 & 22.1 & 9.9 & 0.6 & 100.0 & 0.2 & 0.4 & 3.8 & 62.8 & 22.7 & 9.7 & 0.4 & 100.0 \\
\hline Mozambique & 1997 & 3262 & 0.4 & 1.4 & 8.9 & 80.1 & 7.7 & 1.5 & 0.1 & 100.0 & 0.3 & 1.3 & 10.5 & 79.3 & 7.0 & 1.5 & 0.1 & 100.0 \\
\hline Namibia & 1992 & 2225 & 0.9 & 2.1 & 10.2 & 65.9 & 13.9 & 6.7 & 0.4 & 100.0 & 0.9 & 1.7 & 10.5 & 64.7 & 15.0 & 6.9 & 0.3 & 100.0 \\
\hline Nepal & 1996 & 3286 & 1.6 & 4.8 & 19.4 & 72.5 & 1.6 & 0.1 & 0.0 & 100.0 & 2.4 & 5.5 & 25.3 & 65.4 & 1.3 & 0.1 & 0.0 & 100.0 \\
\hline Nicaragua & $1997 / 98$ & 12272 & 0.2 & 0.7 & 3.4 & 53.5 & 28.7 & 12.4 & 1.0 & 100.0 & 0.3 & 0.5 & 4.3 & 54.1 & 28.1 & 11.9 & 0.9 & 100.0 \\
\hline Niger & 1992 & 3436 & 1.7 & 3.4 & 13.6 & 73.8 & 6.3 & 1.1 & 0.0 & 100.0 & 1.7 & 2.5 & 15.0 & 72.4 & 7.1 & 1.3 & 0.0 & 100.0 \\
\hline Niger & 1998 & 3566 & 0.9 & 3.2 & 16.3 & 72.2 & 5.9 & 1.5 & 0.0 & 100.0 & 0.8 & 2.6 & 16.4 & 72.1 & 6.3 & 1.7 & 0.1 & 100.0 \\
\hline Peru & $1991 / 92$ & 4805 & 0.0 & 0.1 & 0.9 & 59.0 & 31.2 & 8.5 & 0.3 & 100.0 & 0.0 & 0.1 & 1.6 & 62.4 & 28.5 & 7.2 & 0.2 & 100.0 \\
\hline Peru & 1996 & 9892 & 0.0 & 0.1 & 1.0 & 54.1 & 35.5 & 9.0 & 0.3 & 100.0 & 0.1 & 0.1 & 1.4 & 58.0 & 32.7 & 7.5 & 0.2 & 100.0 \\
\hline Senegal & $1992 / 93$ & 2936 & 1.4 & 2.3 & 11.1 & 69.5 & 12.0 & 3.4 & 0.2 & 100.0 & 1.2 & 1.7 & 10.9 & 68.9 & 13.2 & 3.9 & 0.2 & 100.0 \\
\hline Tanzania & $1991 / 92$ & 4491 & 0.4 & 1.4 & 7.5 & 79.7 & 9.3 & 1.8 & 0.0 & 100.0 & 0.4 & 1.3 & 9.3 & 78.1 & 9.0 & 1.8 & 0.0 & 100.0 \\
\hline Tanzania & 1996 & 3807 & 0.6 & 1.8 & 6.7 & 77.5 & 10.9 & 2.3 & 0.1 & 100.0 & 0.8 & 1.4 & 8.0 & 76.8 & 10.6 & 2.3 & 0.1 & 100.0 \\
\hline Togo & 1998 & 3186 & 0.6 & 1.2 & 9.0 & 78.0 & 9.0 & 2.1 & 0.2 & 100.0 & 0.8 & 0.9 & 9.4 & 77.0 & 9.3 & 2.4 & 0.2 & 100.0 \\
\hline Turkey & 1993 & 2395 & 0.0 & 0.3 & 2.1 & 47.3 & 31.7 & 17.6 & 0.9 & 100.0 & 0.0 & 0.3 & 2.5 & 48.0 & 31.2 & 17.2 & 0.7 & 100.0 \\
\hline Uganda & 1995 & 3381 & 0.4 & 1.3 & 8.2 & 81.7 & 7.3 & 1.1 & 0.0 & 100.0 & 0.4 & 1.1 & 9.0 & 80.7 & 7.7 & 1.0 & 0.0 & 100.0 \\
\hline Uzbekistan & 1996 & 4070 & 0.8 & 1.6 & 7.8 & 68.2 & 16.2 & 5.1 & 0.2 & 100.0 & 0.6 & 1.3 & 8.2 & 67.0 & 17.5 & 5.2 & 0.2 & 100.0 \\
\hline Zambia & 1992 & 3271 & 0.5 & 1.8 & 8.5 & 75.2 & 11.7 & 2.3 & 0.0 & 100.0 & 0.5 & 1.6 & 9.9 & 73.7 & 11.8 & 2.4 & 0.0 & 100.0 \\
\hline Zambia & 1996 & 3850 & 0.5 & 1.0 & 7.5 & 78.1 & 10.6 & 2.2 & 0.1 & 100.0 & 0.5 & 0.7 & 8.6 & 76.4 & 11.3 & 2.3 & 0.1 & 100.0 \\
\hline Zimbabwe & 1994 & 1908 & 0.1 & 0.6 & 4.3 & 72.0 & 17.3 & 5.6 & 0.1 & 100.0 & 0.2 & 0.4 & 4.5 & 70.9 & 18.0 & 5.9 & 0.1 & 100.0 \\
\hline Total & & 167455 & 0.6 & 1.6 & 7.2 & 65.1 & 18.4 & 6.7 & 0.4 & 100.0 & 0.7 & 1.4 & 8.2 & 64.6 & 18.3 & 6.4 & 0.4 & 100.0 \\
\hline
\end{tabular}




\section{Functional outcomes: age group}

Four reproductive outcomes were tabulated according to both the BMI standards for age groups 15-24, 25-34 and 35-49 years (Table 6). In general, mortality rates were lower the higher the value of either BMI. As expected, the mortality rates were 'U'-shaped with respect to age. Mortality rates for low BMI in each standard within each age group were very similar, although mortality rates for high BMI within each age group were generally lower when based on the de facto standard than on the Quetelet. These differences were greatest for women 15-24 years old, and were larger the greater the age range of the mortality rate. However, the neonatal mortality rate for 15-24-year-old women with a high BMI according to the de facto standard was slightly higher than that of women with a high BMI according to the Quetelet standard. The differences in mortality rates between low and high categories were mostly greater in the de facto standard than in the Quetelet standard.

For both size at birth and birth weight, women classified as low BMI in either standard were more likely to have had a small sized baby or one with a low birth weight than one with either a normal or high BMI. Again, the de facto standard gave a somewhat better distinction in terms of difference in low birth weight or small size by level of BMI.

Pregnancies that did not terminate in a live birth, i.e. ending either by a miscarriage or a still birth, were more likely to have occurred to high BMI women 25 years and over. For women under 25 years old, terminated pregnancies were more likely to have occurred if the woman had either a low or a high BMI than for women with a normal BMI. Again, the differences by BMI category given by the de facto standard were wider than that given by the Quetelet standard.

\section{Functional outcomes: beight group}

The four reproductive outcomes were also tabulated according to both of the BMI standards by height groups $<145 \mathrm{~cm}, 145-159 \mathrm{~cm}$ and $160-200 \mathrm{~cm}$ (Table 7). These groups were chosen to represent women above and below the average height of the elite women (rounded up from $158 \mathrm{~cm}$ ). The below average group was divided into women $<145 \mathrm{~cm}$, who are known to be at greater risk of delivery complications due to small pelvic structure ${ }^{15}$. For women in all height groups, infant and child mortality is lower the higher the value of either BMI. Women who were both short and of low BMI, irrespective of the index, had a much higher neonatal mortality rate; otherwise the difference by height was not large. In general, the trends are similar between both the Quetelet and de facto indices. The dispersion between low and high BMI groups is greater for the de facto index for tall women for infant and under-five mortality but the opposite is true for under-five mortality for short women.

For both size at birth and birth weight, women classified as low BMI in either standard were more likely to have had 
a small sized baby or one with a low birth weight than one with either a normal or high BMI. Again, the de facto standard gave a slightly better distinction in terms of difference in small size by level of BMI but not in birth weight.

Pregnancies that did not terminate in a live birth were more likely to have occurred to low and to high BMI women in each of the height groups using the de facto index. Using the Quetelet BMI, the percentage with a nonlive birth termination was greater the higher the index among women $145-200 \mathrm{~cm}$.

\section{Discussion}

A feature of the age-based curves of NHANES I \& II is that weight increases linearly with height. The different agebased curves tend to be parallel to each other, with older women being heavier for a given height. The exception is the curve for those 18-24 years old, which is flatter than for the older age groups. Using the same dataset, but on a frame-size basis, a different pattern emerges. For large framed women, the trend is for weight to decline with increasing height, for medium framed women the trend is concave from below in shape, and for small framed women the curve is slightly concave. The de facto DHS curve for elite women shows that the 'ideal' weight for a given height is convex in shape, i.e. 'ideal' weight increases faster than height for shorter women but the opposite is true for taller women. Because elite women in the de facto DHS reference are thinner than those in the NHANES I \& II reference, fewer women are defined as undernourished and slightly more as overnourished using this reference compared with the NHANES I \& II references.

The standard definition for an appropriate weight-forheight (Quetelet BMI) is based on the association between BMI and optimal life expectancy of US adults over 25 years old who had taken out life insurance policies with the Metropolitan Life Insurance Company in the early $1940 s^{13,14}$. The relationship between BMI and mortality at both ends of the BMI distribution, however, is unknown for developing countries ${ }^{16}$. Cut-off points have been established to define chronic energy deficiency for the Quetelet $\mathrm{BMI}^{16}$ and applied in studies on mortality ${ }^{17}$, risk of premature births ${ }^{18}$, prenatal supplementary feeding ${ }^{19}$, and worker efficiency, morbidity and mortality ${ }^{20}$. However, these values depart from the desired constant when 'ideal' weights from the references are used. This is reflected in the difference in the proportion of elite mothers defined as having a low and high BMI. In other words, the NHANES I \& II references define more women as having a high BMI, i.e. as being overnourished, than the de facto curve but the opposite is true for having a low BMI, i.e. being undernourished.

The Quetelet BMI is based on a quadratic relationship between weight and height. Our results indicate that, for 
women of reproductive age, a more appropriate exponent for height is 1.63 rather than 2.0. In an investigation of the Benn index using data from NHANES $\mathrm{II}^{21}$, the calculated Benn index was 1.62 for women 18-34 years old, which compared with a coefficient of log height of 1.64 . However, the Benn index and coefficient of log height for 35-54-year-old women were 1.21 and 1.27, respectively. We did not run separate log regressions for each age group but rather included age in the single log regression as an adjustment to the log constant term. The adjustments were found to be less than $2 \%$ (about $1.1 \mathrm{~kg}$ ) between ages 20-24 and ages 35-39 and 40-49 years.

In 14 of the 35 countries surveyed, the predicted values of weight given height and age were significantly different to those for the Dominican Republic. Higher average weights of the elite women occurred in Egypt, Morocco and Turkey in the Near East/North Africa region, in Guatemala, Nicaragua and Peru in Latin America, and in Ghana, Niger, Tanzania and Zimbabwe in sub-Saharan Africa. Four countries had significantly lower average weights: Bangladesh, Nepal, Kyrgyz Republic and Uzbekistan. These differences were controlled for in the estimation of the de facto standard.

Among children, greater height-for-age implies a better nutritional status. For women this is not the case. Tables 2 and 5 show that being tall does not necessarily indicate a woman is well-nourished. Nine of the 10 surveys with the tallest women were from sub-Saharan Africa, but these surveys ranked within the first 14 highest levels of prevalence of women with low BMI. In contrast, many of the countries whose women were the shortest, e.g. Guatemala, Peru and Bolivia, had women with the least prevalence of low BMI. In a third group of countries, notably Nepal and Bangladesh, most women are both short and of low BMI. However, a rank correlation test gave a Spearman's rho of $0.53(P=0.000)$, indicating that there was a moderate level of correlation between low height and low BMI (wt/ht ${ }^{2}$ ).

In a healthy adult population, $3-5 \%$ of adults have a Quetelet BMI $<18.5^{11}$. WHO also proposed a somewhat arbitrary classification for nutritional status that endeavours to take into consideration functional impairments such as work capacity, work productivity, and adult mortality and morbidity. If 5-9\% of the population has a $\mathrm{BMI}<18.5$, nutritional monitoring is required; if $10-19 \%$ are in this category, the nutritional situation is poor; if $20-$ $39 \%$, the situation is serious; and if $>40 \%$, the situation is critical. Among the 46 surveys included here, only 12 fell within the range for a healthy population; 13 required nutritional monitoring; in 17 the nutritional status was classified as poor; in three it was serious; and in one it was critical.

The strengths of this analysis are that it is based on a large number of non-pregnant women of reproductive age from various ethnic groups, thus it is not biased by genetic selection; the data are nationally representative and from a large number of developing countries; the sample size allowed estimation of neonatal, infant and under-five mortality within nutritional status groups without being subject to large sampling variability; and the constructed dataset allowed estimation of both under- and overnutrition.

The limitations are that the data are based on women with children under 5 years old rather than on all women of reproductive age (15-49 years old); a selection bias exists for younger women who are not yet married, especially those under 20 years old; and the women identified as being elite were unequally distributed by country because the data were based on nationally representative samples and some countries are more developed than others. An important caveat in the analyses relating functional outcomes to nutritional status is that nutritional status was taken at the time of the survey, while the functional outcomes pertained to the five-year period preceding the survey. Unless a prospective study is done, the latter is unavoidable.

This analysis, based on national level data from 46 surveys, supports the use of the Quetelet BMI in developing countries, despite the fact that it was developed from data on the US population. The de facto standard developed here has somewhat higher discriminatory power in identifying differences in functional outcomes, namely neonatal, infant and under-five mortality, birth weight and birth size, and adverse pregnancy outcomes. However, the convenience of using 2 as an exponent in the Quetelet BMI, rather than 1.6 in the de facto index, outweighs the advantage of the de facto index in classifying nutritional status of women. In his 1971 study of a power-type weight-for-height index as a measure of adiposity, Benn came to a similar conclusion $^{22}$.

\section{Acknowledgements}

This work was supported by the USAID Measure/DHS+ Project under contract no. HRN-C-00-97-00019-00 and the Food and Nutrition Monitoring Project (IMPACT) under contract no. DAN-5110-Q-00-0014-00.

\section{References}

1 Steyn K, Bourne L, Jooste P, Fourie JM, Rossouw K, Lombard C. Anthropometric profile of a black population of the Cape Peninsula in South Africa. East Afr. Med. J. 1998; 75(1): $35-40$.

2 Berdasco A. Body mass index values in the Cuban adult population. Eur. J. Clin. Nutr. 1994; 48(Suppl. 3): S155-S163.

3 Ge K. The body mass index of Chinese adults in the 1980s. Eur. J. Clin. Nutr. 1994; 48(Suppl. 3): S148-54.

4 Giay T, Khoin HH. The use of body mass index in the assessment of adult nutritional status in Vietnam. Eur.J. Clin. Nutr. 1994; 48(Suppl. 3): S124-30.

5 Frisancho AR. New standards of weight and body 
composition by frame size and height for assessment of nutritional status of adults and the elderly. Am. J. Clin. Nutr. 1984; 40: 808-19.

6 Nutrition Canada. Anthropometry Report: Height, Weight, and Body Dimensions. Ottawa: Bureau of Nutritional Sciences, Health Protection Branch, Health and Welfare, 1980.

7 Frisancho AR, Flegal PN. Elbow breadth as a measure of frame size for United States males and females. Am. J. Clin. Nutr. 1983; 37: 311-4.

8 Rosenbaum S, Skinner PK, Knight IB, Garrow JS. A survey of heights and weights of adults in Great Britain, 1980. Ann. Hum. Biol. 1985; 12: 115-27.

9 Metropolitan Life Insurance Company. Metropolitan height and weight tables. NY Stat. Bull. 1983; 64: 1-9.

10 World Health Organization (WHO). Physical Status: The Use and Interpretation of Anthropometry. WHO Technical Report Series, No. 854. Geneva: WHO, 1995.

11 Bray GA, ed. Obesity in Perspective, Part 1. Publication No. 75-851. Bethesda, MD: Fogarty International Center, National Institutes of Health, 1975.

12 Lee J, Kolonel LN, Hinds MW. Relative merits of the weightcorrected-for-height indices. Am. J. Clin. Nutr. 1981; 34: 2521-9.

13 Metropolitan Life Insurance Company. Ideal weights for women. NY Stat. Bull. 1942; 23: 6.

14 Metropolitan Life Insurance Company. Ideal weights for men. NY Stat. Bull. 1943; 24: 6.

15 Krasovec K, Anderson MA, eds. Maternal Nutrition and Pregnancy Outcomes. Scientific Publication No. 529. Washington, DC: Pan American Health Organization, 1991.

16 James WPT, Ferro-Luzzi A, Waterlow JC. Definition of chronic energy deficiency in adults: Report of a working party of the International Dietary Energy Consultative Group. Eur. J. Clin. Nutr. 1988; 42: 969-81.

17 Naidu AN, Rao NP. Body mass index: a measure of the nutritional status in Indian populations. Eur. J. Clin. Nutr. 1992; 48(Suppl. 3): S131-4.

18 Naidu AN, Neela J, Rao NP. Maternal body mass index and birth weight. Nutr. News 1991; 12(2).

19 Kusin JA, Houtkooper JM. Energy supplementation during pregnancy and postnatal growth. Lancet 1992; 340: 1294-6.

20 Shetty PS, James WPT. Body Mass Index: A Measure of Chronic Energy Deficiency in Adults. Rome: United Nations Food and Agriculture Organisation, 1994.

21 Flegal K. Ratio of actual to predicted weight as an alternative to a power-type weight-height index (Benn index). Am J. Clin. Nutr. 1990; 51: 540-7.

22 Benn RT. Some mathematical properties of weight-forheight in indices used as a measure of adiposity. Br. J. Prev. Soc. Med. 1971; 25: 42-50.

\section{Appendix A: Values for country $(C)$ and their $t$-values}

\begin{tabular}{|c|c|c|}
\hline Country & $C$ & $t$-value \\
\hline Bangladesh & -0.042 & -8.467 \\
\hline Benin & 0.014 & 1.051 \\
\hline Bolivia & 0.002 & 0.492 \\
\hline Brazil & -0.006 & -1.726 \\
\hline Burkina Faso & 0.014 & 1.848 \\
\hline Central African Republic & -0.021 & -1.295 \\
\hline Chad & 0.004 & 0.251 \\
\hline Colombia & 0.003 & 0.592 \\
\hline Comoros & -0.009 & -0.367 \\
\hline Cote d'Ivoire & -0.001 & -0.060 \\
\hline Egypt & 0.062 & 21.066 \\
\hline Ghana & 0.037 & 2.408 \\
\hline Guatemala & 0.030 & 6.490 \\
\hline Haiti & -0.005 & -0.410 \\
\hline Kazakstan & 0.002 & 0.597 \\
\hline Kenya & 0.002 & 0.225 \\
\hline Kyrgyz Republic & -0.018 & -5.697 \\
\hline Madagascar & -0.052 & -1.503 \\
\hline Mali & 0.002 & 0.213 \\
\hline Malawi & 0.017 & 1.026 \\
\hline Morocco & 0.013 & 2.110 \\
\hline Mozambique & 0.008 & 0.509 \\
\hline Namibia & 0.010 & 1.692 \\
\hline Nepal & -0.048 & -4.055 \\
\hline Nicaragua & 0.008 & 2.306 \\
\hline Niger & 0.031 & 3.997 \\
\hline Peru & 0.010 & 3.377 \\
\hline Senegal & 0.021 & 1.885 \\
\hline Tanzania & 0.035 & 2.902 \\
\hline Togo & 0.002 & 0.207 \\
\hline Turkey & 0.015 & 2.683 \\
\hline Uganda & 0.033 & 1.639 \\
\hline Uzbekistan & -0.018 & -6.261 \\
\hline Zambia & -0.005 & -0.707 \\
\hline Zimbabwe & 0.033 & 4.522 \\
\hline
\end{tabular}

